\title{
Article \\ Influence of Regulatory Fit Theory on Persuasion from Google Ads: An Eye Tracking Study
}

\author{
Yessica-Ileana Giraldo-Romero, Carmen Pérez-de-los-Cobos-Agüero, Francisco Muñoz-Leiva (D), \\ Elena Higueras-Castillo * and Francisco Liébana-Cabanillas (1)
}

check for updates

Citation: Giraldo-Romero, Y.-I.; Pérez-de-los-Cobos-Agüero, C.; Muñoz-Leiva, F.; Higueras-Castillo, E.; Liébana-Cabanillas, F. Influence of Regulatory Fit Theory on Persuasion from Google Ads: An Eye Tracking Study. J. Theor. Appl. Electron. Commer. Res. 2021, 16, 1165-1185. https:// doi.org/10.3390/jtaer16050066

Academic Editor: María

Teresa Ballestar

Received: 2 February 2021

Accepted: 26 March 2021

Published: 31 March 2021

Publisher's Note: MDPI stays neutral with regard to jurisdictional claims in published maps and institutional affiliations.

Copyright: (c) 2021 by the authors. Licensee MDPI, Basel, Switzerland. This article is an open access article distributed under the terms and conditions of the Creative Commons Attribution (CC BY) license (https:// creativecommons.org/licenses/by/ $4.0 /)$.
Marketing and Market Research Department, Faculty of Economic and Business Sciences, University of Granada, 18011 Granada, Spain; e.jessigiraldo@go.ugr.es (Y.-I.G.-R.); carmencobos16@gmail.com (C.P.-d.-1.-C.-A.); franml@ugr.es (F.M.-L.); franlieb@ugr.es (F.L.-C.)

* Correspondence: ehigueras@ugr.es

\begin{abstract}
Search engine marketing accounts for a high percentage of investment in platforms such as Google. Several studies have confirmed that users have a negative bias towards advertisements, so we apply social psychology theories via the elaboration probability model in this analysis. In this research, we modify the types of ads shown on Google's results pages using the regulatory focus and fit and message framing theory to study attentional and behavioral responses with eye-tracking technology and cognitive responses from self-report measures. The results confirm a negative bias towards ads and a preference for organic results. Although promotion-framed ads seem to be more persuasive than neutral and prevention-framed ads, it was not possible to prove compliance with regulatory fit in this field through survey-based studies.
\end{abstract}

Keywords: Google; SEM; regulatory fit; elaboration probability model; message framing; eye tracking

\section{Introduction}

It is now widely recognized that search engines offer significant opportunities for brands to increase the visibility of their websites, to gain new potential customers and to open up new markets. Search engine marketing (SEM) involves displaying advertisersponsored results in the top rankings of search engines based on the queries or keywords entered by users [1]. In recent years, SEM has gained great popularity in the field of digital marketing. Investment in search engine advertising now represents between 35\% and $47 \%$ of the total investment in online advertising [2]. In particular, Google is the main source for searches by Spanish residents and accounted for $96 \%$ of queries in 2019 [3]; the majority of SEM strategies used by companies are therefore implemented on Google. Although SEM is the preferred method used by companies to gain visual impact quickly and exponentially, it has been empirically demonstrated that users largely ignore ads, even to the point of rejection [4-9], and this negatively affects the return on investment that companies can expect. It is therefore recommended that marketers use strategies that integrate SEM with search engine optimization (SEO) to launch both short- and long-term actions to persuade users via sponsored and organic content by increasing the effectiveness of their marketing actions [10]. With this in mind, it is necessary to find effective solutions that can help marketers and companies to decrease the rejection of advertisements (henceforth referred to as ads) by users and to increase the changes for persuasion.

In academia, the interest in researching user behavior on Search Engine Results Page (SERP) has been prominent for the last two decades and has been increasing [11-13]. In particular, there is work focusing on the level of user attention between organic and paid results in SERPs [14], the attitude towards ads in SERPs $[4,7,9,15]$, the factors influencing user interaction with ads [6], the effectiveness of SERP ads [16,17], the impact of the quality and position of SERP ads [4] or the influence of regulatory fit theory on the persuasiveness of SERP ads $[8,18]$. Although the literature has analyzed ways of increasing advertising 
effectiveness from various perspectives very little has been proposed in relation to the use of social psychology theories as a means of increasing the persuasiveness of ads. Current efforts are not really effective, as the ads do not capture the user's attention, do not achieve the expected interaction and, finally, do not make enough of an impact for the user to remember the ad. Generally, advertisers do not focus on the motivational orientation of the user-that is, they do not focus their keywords and advertising messages according to the motivational focus of each person; instead, they use general keywords and abstract messages without any personalization and therefore without taking into account the user's information needs. Some advertisers even neglect consistency between their advertising messages and the content of the links on their websites [8]. Of course, all of these elements greatly weigh towards a negative perception of advertisements. There has been, however, little research on the persuasiveness of SERP ads on users. We also found no significant studies linking regulatory fit theory and SERP ads with eye tracking, which is a tool that has already been used to test the effectiveness of the persuasiveness of advertising messages [19]. An opportunity therefore arises to implement social psychology theories of persuasion, such as message framing theory, regulatory approach and regulatory fit, and the elaboration probability model (ELM), which are, accordingly, applied in this work. There is a gap in the study of how this theory affects or influences the persuasive power of SEM ads on users from an attention level, interaction, and recall perspective, thus complementing the non-existent literature. In short, the aim of this research is to evaluate the influence of the theory of regulatory fit on the persuasiveness of advertising messages versus organic results - that is, the product of transactional searches-through eye-tracking technology. Five specific objectives are proposed to achieve this:

1. To test the degree of visual attention generated towards ads with orientation versus organic results.

2. To evaluate whether there are differences in clicking behavior when subjects view ads with messages that are framed based on the focus versus organic results.

3. To check whether there are changes in the subjects' attitudes after viewing a set of motivation-oriented ads.

4. To explore whether there is more visual attention towards ads and more clicking behavior in individuals with regulatory fit.

To achieve the above objectives, a mixed experimental design (both within-subject and between-group) was created. During a collection method based on a centrally located Hall Test, a group of 15 participants were individually asked to visualize three different stimuli from a representation of a Google page made up of ads and organic results. The ad messages were manipulated in two of the three conditions by personalizing them based on the two regulatory approaches (promotion vs. prevention). To obtain biometric results, the Tobii Pro Nano tool was used together with Tobii Pro Lab software and a set of eye metrics, and the number of clicks was recorded to measure click behavior.

Recently, the work of Saura [20] has identified the different uses and applications pursued by data sciences, which facilitate decision-making and extraction of actionable insights and knowledge in the digital environment; however, the management of data sciences to large datasets in digital marketing remains scarce. The focus of the present work can thus be framed within data mining techniques, and following the guidelines of Saura [20], we will try to discover knowledge of user behavior in SERP.

This remainder of the paper is structured as follows. First, we discuss the proposed theoretical framework and explain the theories mentioned above, their relationship with the present study and our approach to the research hypotheses. The methodology section describes the experiment and interprets the results. Next, the conclusions and managerial implications are presented, and finally, the limitations are acknowledged, and future lines of research are proposed. 


\section{Theoretical Background}

Regulatory fit theory is based on the two types of self-regulatory guidelines that motivate people to reach a desired end state: focusing on obtaining pleasure and/or avoiding pain or loss. These orientations can be described using the expressions "promotion" and "preventive" focus or approach. In the promotion orientation, the realization of ideals, aspirations, and achievements are interpreted as pleasure and the absence of these is interpreted as pain [21]. This translates as the pursuit of gain or profit in the presence of positive outcomes or the avoidance of non-profit in the absence of positive outcomes, so that, in their pursuit of a desired end state oriented towards success, they will strive harder to achieve growth and avoid errors of omission [22-24]. In the preventive orientation, pleasure is interpreted as the fulfilment of obligations and responsibilities and their absence is interpreted as pain [21]. The goal here is to achieve safety and security, adopting strategic vigilant means, which causes such individuals to make less effort to avoid making mistakes, as they are more sensitive to losses and experience the absence of negative outcomes as non-losses and the presence of negative outcomes as losses [24,25]. In summary, these two orientations divide people into those who are more enthusiastic or anxious and those who are more motivated and put more effort (higher level of information processing) into obtaining benefits, gains, or positive outcomes. The latter are more vigilant, duty-focused, and focused on fulfilling their responsibilities; they are more motivated to achieve security and avoid losses and negative outcomes. These people have a low level of elaboration, as they are content to process the necessary information to avoid making mistakes [25]. Thus, regulatory focus theory is premised on the idea that there is a match or adjustment between a person's motivation and the strategic means they use to achieve their objectives. When this happens, the intensity of the motivation increases and a sense of alignment appears between what is being done and how the objectives are being achieved [26,27]. The hypotheses of this paper are based on regulatory fit theory, which states that people have a self-regulating motivational system that they use to pursue their goals. This system, which can be analyzed using the promotional or preventive orientation discussed above, plays an important role in the choice of products or services and influences the effectiveness of advertising messages in persuading consumers [28]. Based on these assumptions, regulatory fit theory emerges, which according to Higgins [29] arises when people pursue objectives in a way that is compatible with their regulatory fit. This regulatory fit may be chronic or induced [28]. In this line, the study by Xiong et al. [30] used eye tracking to show that behavioral motivation increased when the chronic regulatory focus matched the situational focus. Similarly, Fridman et al. [31] note that when information is presented in a non-fit manner, participants' attitudes are less favorable, while fit messages increase the willingness to process the information.

One effective method of inducing regulatory fit is the implementation of message framing, which involves manipulating the content or characteristics of the message so that it is compatible with how subjects pursue their objectives. Message framing is based on Kahneman and Tversky's [32] prospective theory, which describes how the same information can lead to different choices depending on how it is presented-that is, whether in the form of a loss or a gain. Lee and Aaker [33] describe how regulatory fit is applied in the context of message framing to produce more persuasive messages. They explain that, for a promotion-focused person, a message with a promotion-focused gain frame and low perceived risk will be more persuasive, whereas a message with a prevention-focused loss frame and a high perceived risk will be more effective for a prevention-focused person. Another very clear example of how to apply theories to persuasion is described in the study by Mowle et al. [18], who show that by using regulatory fit theory, the perceived persuasiveness of ads in searches made through search engines such as Google can be influenced or motivated and can therefore affect the decision-making process of clicking on an advertisement.

ELM is a two-fold process theory relating to the formation of and changes in attitude. It integrates the heuristic model and cognitive response theory. ELM also views information 
processing as a continuum where the extremes vary according to the level of processinglow or high. In this way, two routes are developed. First, the central route, which refers to a highly elaborated process, is characterized by the fact that the messages receive greater interest from the receiver as they deeply analyze the content of the message and the strength of the arguments. In addition, they elaborate a series of thoughts around the message and compare what the source is pointing to with their own previous knowledge, feelings and attitudes. It is difficult to construct highly persuasive messages that activate the central route, as it depends strongly on the subject's interest and the complexity of the message. The other route is the peripheral route, for which the person is not motivated or finds it difficult to understand the content of the message. The arguments are not examined but are evaluated on the basis of elements external to the message itself, such as attractiveness, enjoyment, or experience of the source. This route is characterized as a low elaboration process [34]. Therefore, attitudes are created and modified as people process the information they receive and through the cognitive effort that each person must make to process that information. The probability of processing is at the center of the model, because-depending on the way individuals examine and pay attention to arguments-persuasion will be effective by a "central route" (high processing) or a "peripheral route" (low processing) [35]. Attitude changes associated with the central route are the most desirable, as the subject will generate more thoughts about the message, which in turn induces the development of a longer lasting attitude change. In contrast, persuasion via a peripheral route leads to a shorter-lasting attitude change. In this case, it may be more effective in circumstances where the individual does not have sufficient motivation or the ability to process the message extensively. ELM has been applied in the field of marketing and consumer behavior and is widely used in digital marketing strategies [36,37]. Because the study is contextualized in the online domain in terms of Google's SERP, organic results have been categorized as central signals, while sponsored results would be peripheral signals, as there is a bias that negatively influences the motivation to process them.

\section{Research Hypotheses}

Regulatory fit theory plays an important role in attention and message recall [19]. When people focus more on messages that are compatible with their self-regulatory orientation, they pay more attention and a higher processing rate is generated, thus influencing better recall of the information. Likewise, regulatory fit influences the interaction a subject has with the message-specifically by being more willing to click on Google (SEM) ads when it matches their self-regulatory orientation. Li et al. [8] demonstrate that people with a promotion focus are more willing to interact with (click on) ads because they are focused on obtaining useful information from any source. In contrast, prevention-focused individuals tend to avoid (not click on) ads because they see them as irrelevant, so they interact less with them and focus more on organic search results.

Theories such as ELM aid the development of persuasive communication because they start from the basic premise that attitude change attributable to the strength of messages depends on the likelihood that thoughts about them will be generated. In this case, message framing is a strategy that plays an important role in the creation of more or less persuasive messages [38]. Gain or loss messages are closely linked to the regulatory focus of individuals; if the subject emphasizes the pursuit of profit, it will be more persuasive for promotion-oriented individuals. Conversely, ads framed with loss avoidance will be more persuasive for prevention-oriented individuals. Thus, regulatory fit will result in a feeling of liking towards messages framed in a way that is consistent with consumers' orientations [22].

The academic literature shows an increasing number of studies using eye-tracking as well as its strong ability to assess the effectiveness of visual marketing [39-42]. While eye tracking offers information that cannot be obtained with traditional techniques, it also complements traditional techniques by providing more detail [39]. The study by Hervet et al. [43] used eye-tracking to show that most participants look at ads at least once 
during their visit to a website. Also, congruent ads are better memorized than incongruent ads. However, Schultheiß and Lewandowsk [44] have shown that individuals with low knowledge about search advertising are more likely to click on ads than subjects with a high level of knowledge. In addition, those with a low level of knowledge are less likely to search among organic search results. It has also been recently shown that certain aspects such as colors, messages referring to promotion or price or images can influence users' attention [45]. Table 1 summarizes the main findings of recent research that shared similar objectives.

Table 1. Summary of similar research

\begin{tabular}{cl}
\hline \multicolumn{1}{c}{ Reference } & \multicolumn{1}{c}{ Purpose of the Research } \\
\hline Xiong et al. [30] & $\begin{array}{l}\text { The results demonstrate that behavioral motivation is significantly } \\
\text { enhanced, thereby increasing the depth of the preferred mode of } \\
\text { information processing, when the chronic regulatory focus matches the } \\
\text { situational focus. }\end{array}$ \\
\hline Ewe et al. [46] & $\begin{array}{l}\text { The results provide evidence that a message using visual and textual cues } \\
\text { based on a promotion and prevention regulatory focus may trigger a } \\
\text { preference in an investment adviser's product recommendation. }\end{array}$ \\
\hline Fridman et al. [33] & $\begin{array}{l}\text { The results show that when information was presented in a non-fit (vs. fit) } \\
\text { manner, the strength of participants' initial attitude was reduced. }\end{array}$ \\
\hline Wibmer et al. [47] & $\begin{array}{l}\text { The goal of this research was to investigate the effect of two idea } \\
\text { presentation modes on changes in visual attention to idea attributes, } \\
\text { measured with fixations using eye tracking over time. The results show } \\
\text { that visual attention to idea attributes decreases rapidly after participants } \\
\text { saw the first ideas. }\end{array}$ \\
\hline
\end{tabular}

For the above reasons, we used message fit theory to induce regulatory fit and increase persuasion under an eye-tracking-based approach. However, regulatory focus can be chronic or induced [29], so an effective method to induce regulatory adjustment is the implementation of message framing, which consists of manipulating the content or characteristics of the message so that it is compatible with the way in which subjects pursue their goals. According to the literature $[8,18]$, subjects with regulatory fit are more likely to fixate on the types of messages that fit their orientation-that is, promotion-orientated subjects will fixate on promotion-framed ads, and prevention-oriented subjects on preventionframed ads. In general, it is hypothesized that this will result in changes in visual attention to ads, in behavior (through higher numbers of clicks on the ads) and in increased recall of the message [19]. The following hypotheses can therefore be proposed:

Hypothesis 1 (H1). More visual attention will be paid to ads by individuals with regulatory fit (promotion or prevention).

Hypothesis 2 (H2). Click-through will be more prevalent amongst regulatory-fit consumers.

\section{Materials and Methods}

\subsection{General Procedure}

In the first phase of data collection, interviewees completed an online survey on the Qualtrics platform (sampling and pretesting) to record their motivational orientation and their recall and attitude towards both ads and organic results when searching for hotels on the Internet. An experiment was then conducted to create a simulated search engine that was as close as possible to Google. Each subject carried out a search with a set of keywords ("Hotels in Madrid") and three different result pages were displayed containing non-oriented, promotion-oriented and prevention-oriented ads, as well as organic results. To evaluate the impact of the theory of regulatory fit on visual attention and interaction towards both ads and organic results, eye-tracking technology was applied. Furthermore, at 
the end of the experiment, a post-test was performed as a self-report measure to determine whether there was a change in attitude and to check whether the subjects' recall of the ads was higher over the short term.

\subsection{Data Collection}

The sample of participants was selected using the convenience sampling collection method based on the Hall Test-concretely in a centrally located café-and was made up of 15 participants, approximately equally distributed between men and women (46.7\% were men and 53.3\% women), between 18 and 63 years of age (average age: 35.1 years); they were mostly graduates who travelled frequently and who used the Google search engine to find hotel reservations and stay in houses, flats, or hotels during their travels. The gender and age quotas selected reflect the adult Spanish population based on 2019 Census data [48] as well as Internet users [49]. The fieldwork was carried out at a cafe in a city in southern Spain in July 2020.

\subsection{Measurement Scales}

Chronic regulatory fit was measured using the Regulatory Focus Questionnaire proposed by Higgins et al. [29] with a five-point Likert scale (see Appendix A) that differentiates between a prevention focus, which emphasizes safety and accountability, and an advocacy or promotion focus, which emphasizes hope and achievement.

Each participant first filled out the relevant socio-demographic questionnaire containing questions about the frequency with which they used the Google search engine to book hotels and their frequency of travel. The second step involved two blocks of questions about their attitudes towards types of ads and organic results, and about their recall.

Attitude was measured on a five-point Likert scale adapted from Tang et al. [50], recall was measured with an open question and suggested recall with a screening question [41]. The screening question was: "what did the message(s) you remember consist of?" The answers were recoded numerically in SPSS, with a value of one representing recall and zero representing no recall.

\subsection{Eye-Tracking Measurements}

The system used to extract the participants' eye-tracking data was the Tobii Pro Nano Portable Eye-Tracker, a piece of equipment that is $170 \mathrm{~mm}\left(6.7^{\prime \prime}\right)$ long, weighs $59 \mathrm{~g}$ (2.1 oz.) and can be attached to screens of up to 19" (16:9). The experimental design was recreated using Tobii Pro Lab software, the latest software designed by Tobii Pro for human behavior research. The following parameters were used for data analysis: number of fixations or fixation count (FC), first fixation duration (FFD) in milliseconds (ms), total fixation duration (TFD, in ms), total visit duration (TVD, in ms), and mouse click count (MCC).

The FC corresponds to the number of fixations within a given area of interest (AOI); however, this is a very general indicator [51,52] that needs to be complemented with others such as the TFD, FFD, and TVD (the total length of time the participant spent looking at the AOI during the experiment) or MCC on the AOI. These measures are all fixation indicators and reflect the attentional resources allocated to a banner or ad on an Internet page when stimulus information is extracted during eye fixation.

\subsection{Experimental Conditions: Graphic Content}

For the experiment, three pages of Google results were recreated, each showing a set of two ads and a set of three organic results (see Figures 1-3). The aim was to recreate the design of the search engine as closely as possible to avoid confusion for the participants. The messages used were adapted for the consideration of the researchers and considered the following parameters. 


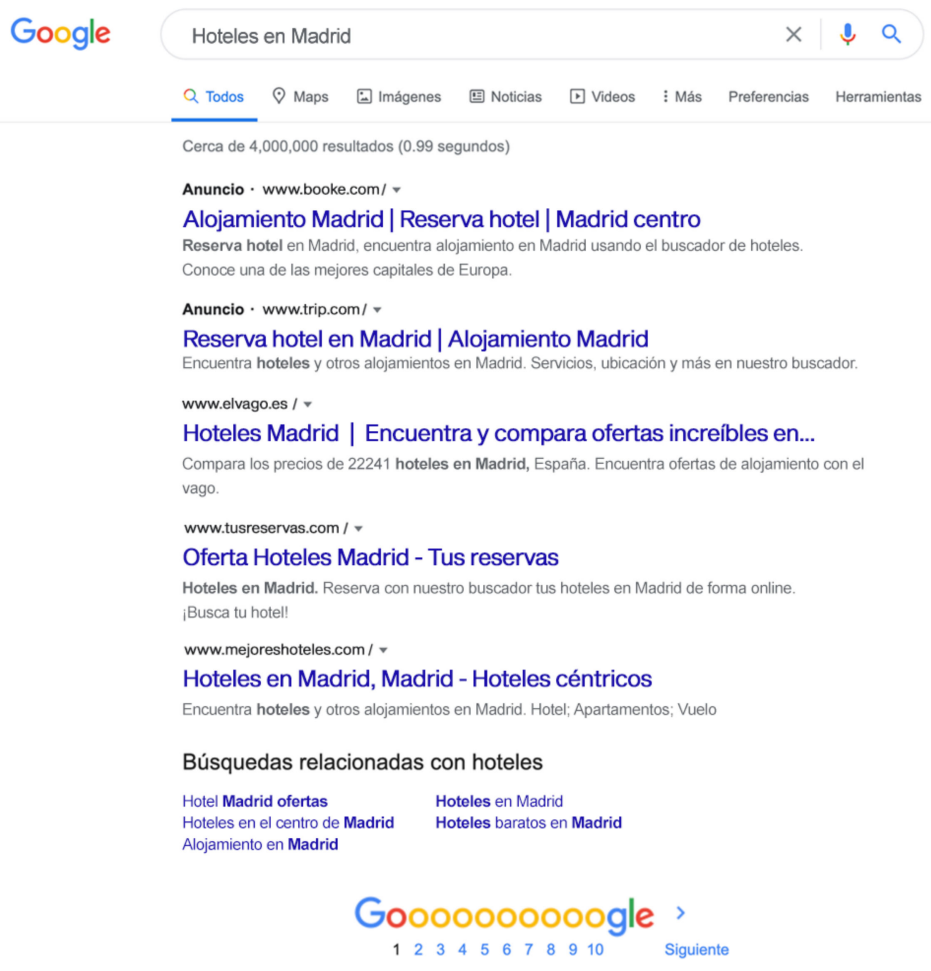

Figure 1. No orientation condition (ASO or neutral).

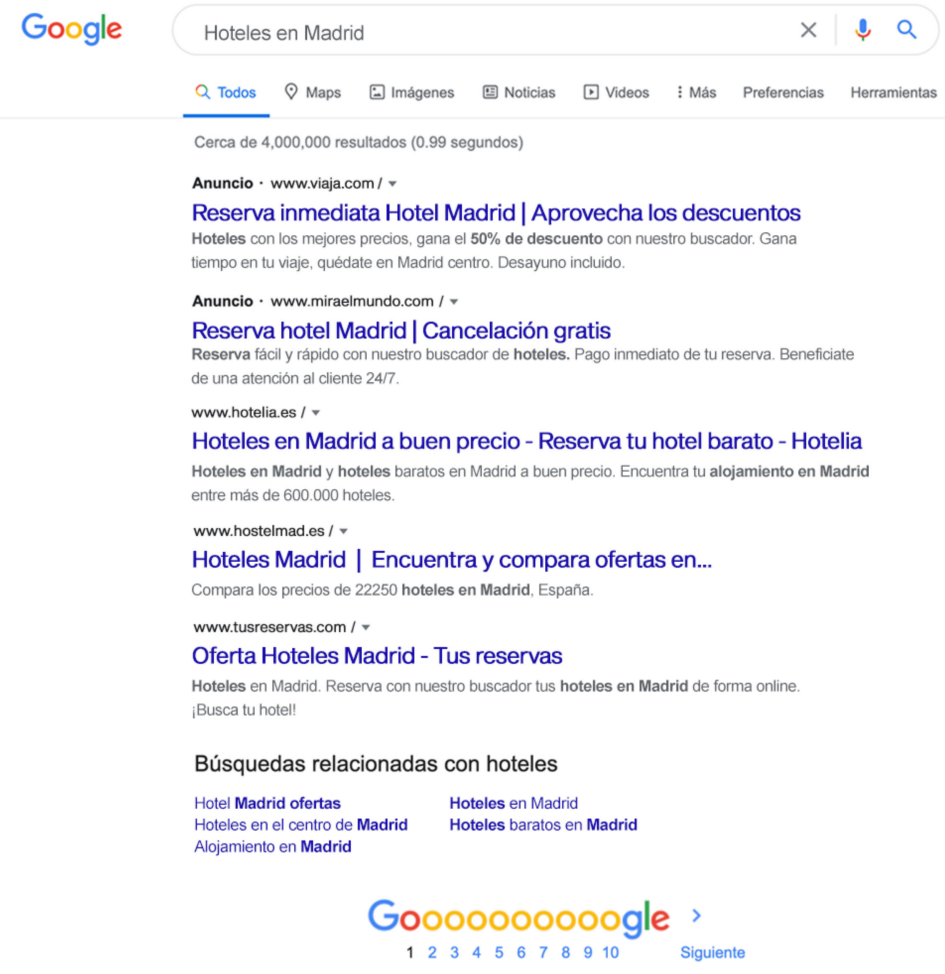

Figure 2. Promotion fit condition (PRO). 


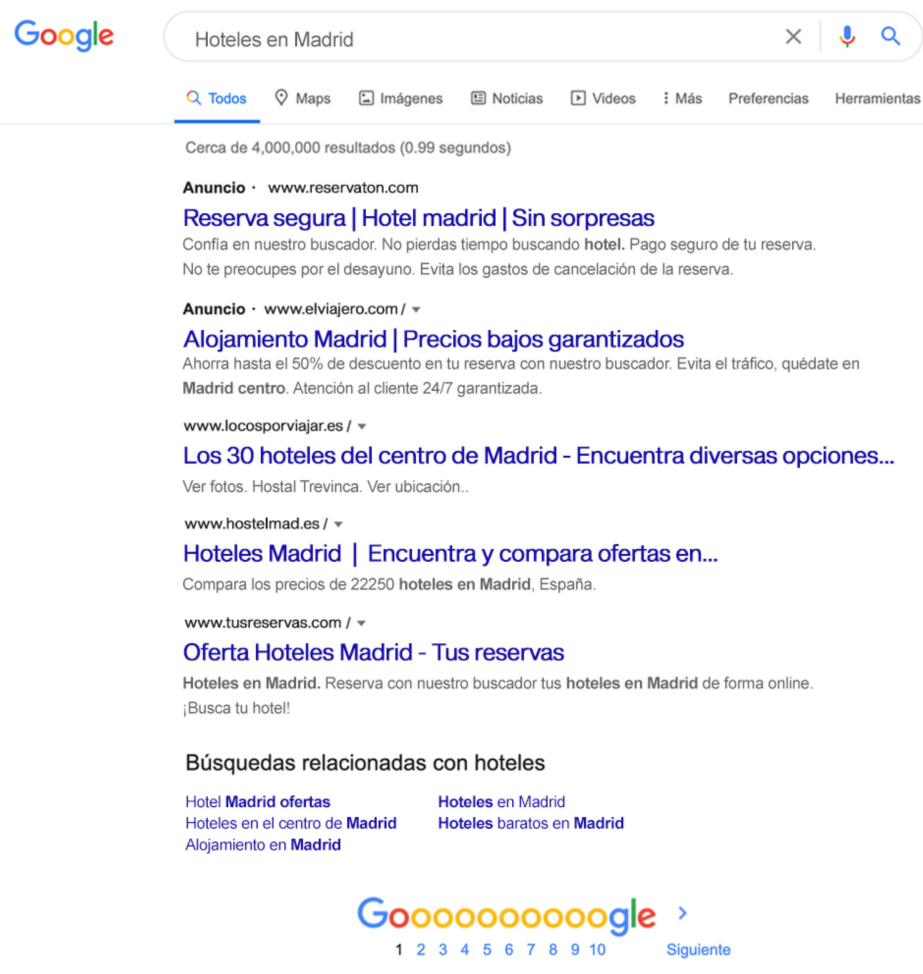

Figure 3. Preventive fit condition (PRE).

First, the Google Ads tool was used to search for the keywords most used when searching for hotels. The most frequent were then chosen for later use in the design of the ad messages. When designing the messages of the organic results, real search results were imitated. Next, because the experimental design was based on testing the influence of the regulatory fit on the persuasiveness of the ads, in two of the three experimental conditions, the ads were oriented according to the promotion (PRO) or prevention (PRE) fit. In the third condition, the ads had no orientation at all (in Spanish: 'anuncio sin orientación'; ASO). In the case of the organic results, messages were designed with neutral messages to avoid influencing the attention and behavior of the subjects. The experimental conditions are shown in Figures 1-3.

Three university professors from the department in which the authors work checked that these ads were clearly oriented towards the corresponding regulatory fit (prevention, neutral, and promotion).

\subsection{Experimental Design}

The experimental design was of a mixed type, combining both within-subject and between-group designs. In the first case (within-subject), each participant was asked to visualize the three manipulated experimental conditions: ads in the Google search engine without orientation with organic results (ASO), ads with orientation towards promotion with organic results (PRO), and ads with orientation towards prevention with organic results (PRE). These were the manipulated variables of the experimental design. To mitigate the possible effect of the presentation of the first stimulus on the rest of the experiment, the display order for the screens was randomized for each subject (counterbalanced design, without replacement).

In the second case (between-group), based on a measurement scale, the group was divided between promotion and prevention participants to determine whether the regulatory fit was fulfilled when each subject was presented with the experimental condition that fitted his or her motivational orientation. This division was also created to evaluate the influence of the regulatory fit on attention, behavior, attitude, and cognitive processing. The dependent variables or observations were the eye-tracking measurements, the number 
of clicks extracted from the eye tracking system and the attitude, cognitive process, and recall data extracted from the self-report questionnaires.

\subsection{Procedure}

When the participants arrived at the location in which the study was carried out, the process was explained to them. It consisted of completing two pre-test questionnaires and a post-test questionnaire at the end of the experiment. In addition, participants were given written consent forms for the experiment to be carried out, which they were asked to sign and give to the research team.

Once these questionnaires were completed, the participants were instructed to adopt a comfortable position in front of the computer to proceed with the eye-tracking calibration and thus start the experiment. The calibration process consisted of a matrix of 13 black points, which were presented prior to the stimuli. The distance between the participant and the screen was checked as being approximately $60 \mathrm{~cm}$. If the calibration was unsuccessful, the process was repeated. The participants then proceeded to perform the experiment as follows (see Figure 4):

1. The first screen to appear contained the instructions and could be changed to the next screen by clicking on the search keywords "Hotels in Madrid". The most general search keywords were chosen to avoid creating confusion and to simplify the task.

2. The second screen showed the Google search bar. After clicking on the "Search" button, the first two-second baseline appeared. The following screens corresponded to the ASO, PRO, and PRE conditions, which were shown at random with a baseline between each. For each screen, the subject was asked to navigate around the page and click on the desired result, but this did not lead to another screen until a period of $30 \mathrm{~s}$ had passed. This was applied to collect more metrics and to be able to control the duration of the stimulus for all participants. The order in which the stimuli were displayed differed between participants.

3. After the three conditions had been displayed, the final screen appeared, on which the participants had to click to finish the task.

\section{Instructions}

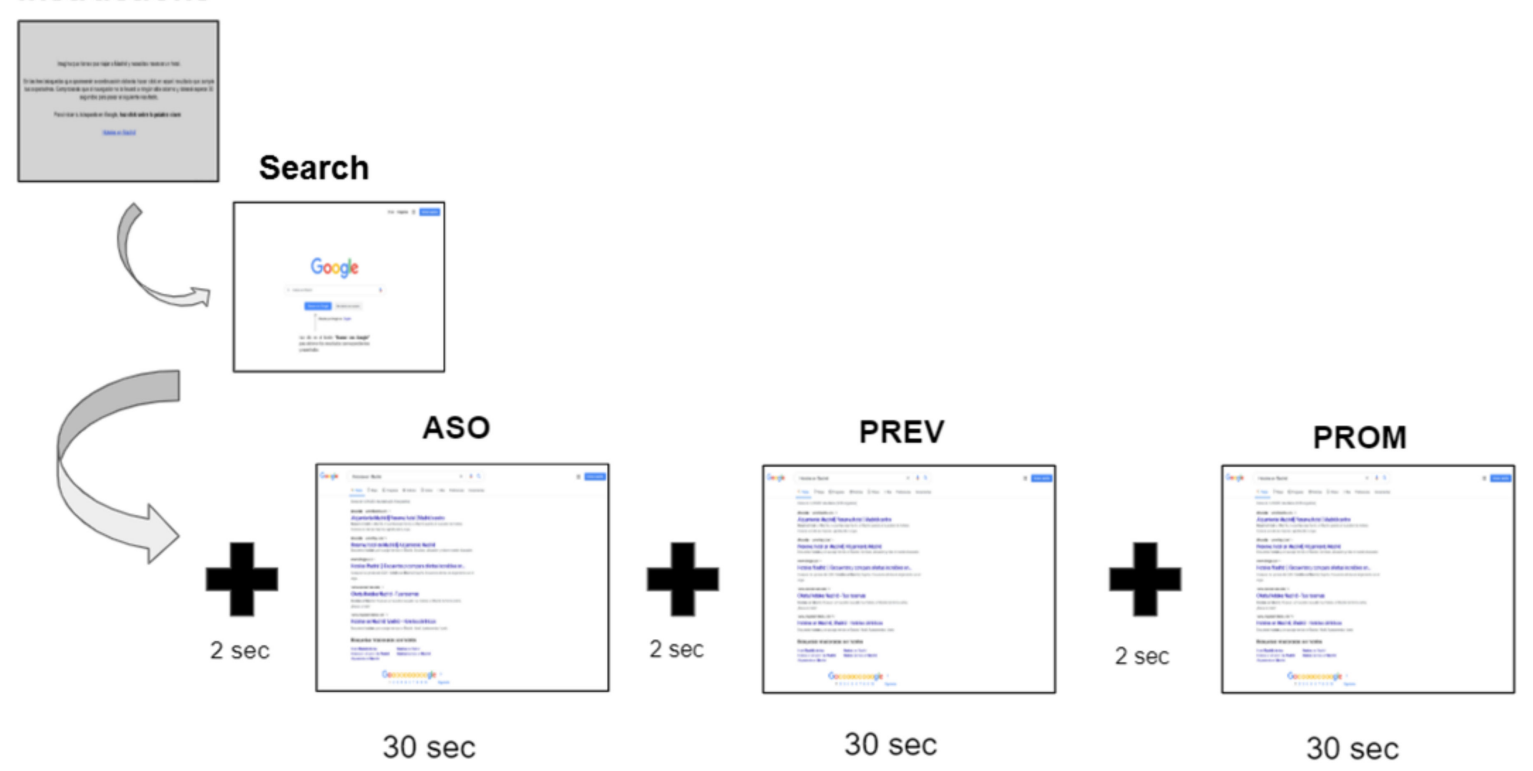

Figure 4. Experimental schedule.

At the end of the test, participants were given a questionnaire about their recall and attitude towards the various types of ads and the organic results. In the analysis phase, Tobii Pro Lab software was used to mark the different AOI to carry out the appropriate 
statistical analyses for the ASO ad set with organic results, the PRO ad set with organic results and the PRE ad set with organic results.

\section{Results}

\subsection{Heat Maps}

The following heat maps show the fixation of the participants under each of the experimental conditions. At first glance, it may appear that the participants read all of the results presented in the ASO condition; however, the fixation was mostly concentrated on the first organic result. According to the literature $[4,6,9,12,14,53-55]$, this pattern of higher concentration on organic results was as expected, due to the general attitude of rejection of ads by users. We therefore found that, in the ASO condition, the participants passed over the ads slightly faster to concentrate more strongly on the organic results (see Figure 5).

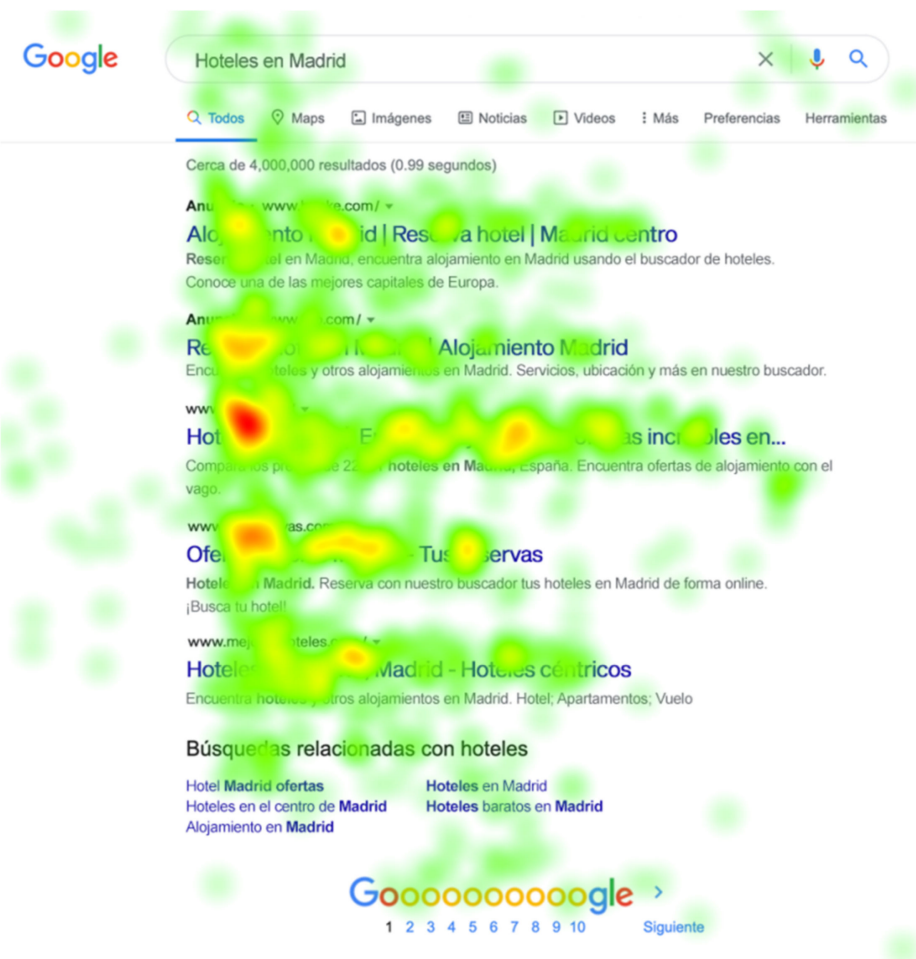

\#

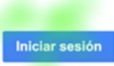

Figure 5. Heat map for the ASO condition.

From a qualitative perspective, it can be observed that the level of fixation for the PRO ads (and also for the organic results) was similar to that for the previous neutral condition (ASO, see Figure 6).

For the PRE condition, it is interesting to note that the concentration of fixation on the organic results was much higher than for the ASO and PRO conditions. This may be due to the fact that, in this condition, the first organic result referred to " 30 hotels in the centre of Madrid", which may have positively fed the rejection of users towards ads; they may have trusted more in this organic result and therefore shown higher fixation. As in the PRO condition, it can be seen that the set of ads for the PRE condition received greater fixation than the set of ads for the ASO condition (see Figure 7). This could be also explained by the fact that prevention-oriented subjects are more likely to pay attention to messages that fit their orientation $[8,18]$. A summary of the results is presented below. 


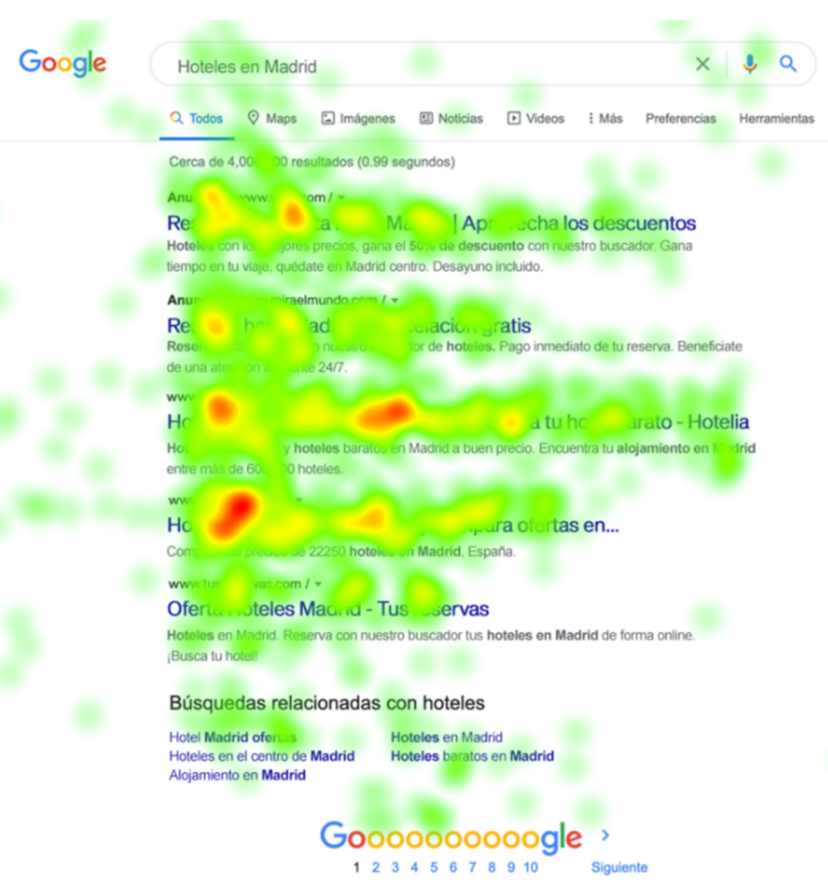

ii:

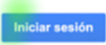

Figure 6. Heatmap for the PRO condition.

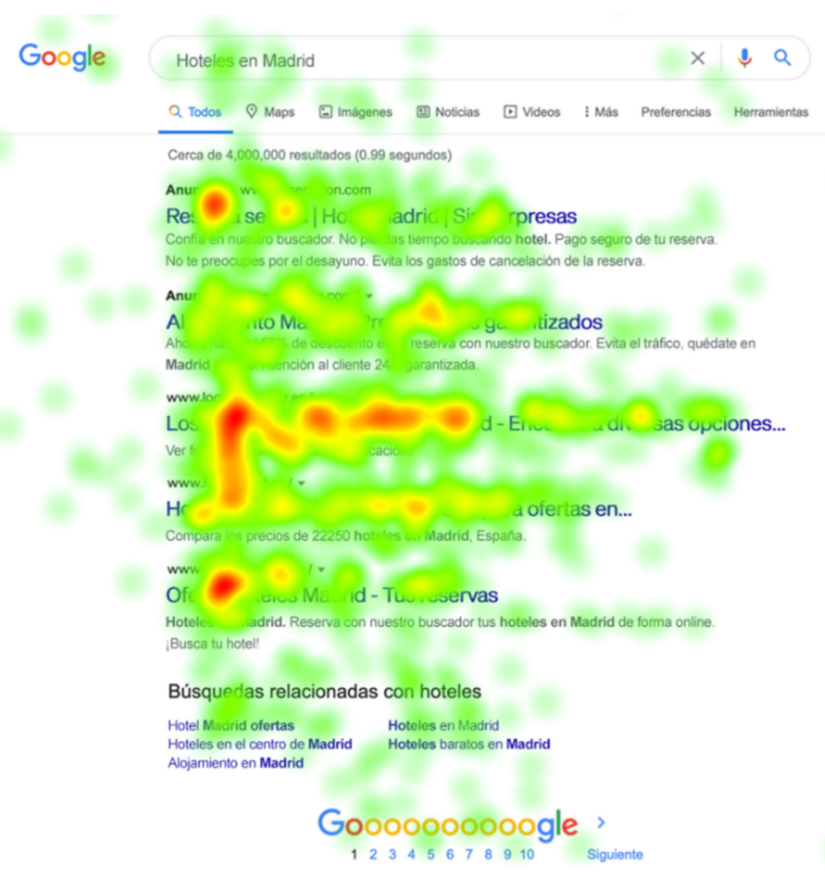

Figure 7. Heatmap for the PRE condition.

\subsection{Initial Manipulation Check}

To check for differences in visual attention between the ad sets and the organic results, a paired/dependent sample $t$-test for mean differences was performed for each AOI set. As expected, most fixation metrics showed significant differences of about $10 \%$, except for the FFD metric on the webpage with the PRO condition (see Table 2). This confirmed that the 
factor was manipulated correctly. It can be observed that the mean values of the fixation metrics for the AOI for the conditions with regulatory fit (PRO and PRE ad sets) are higher than for the ASO ad set, and lower in the PRO and PRE organic result sets with respect to the corresponding ASO condition.

Table 2. Eye-tracking metrics and clicks for ad type vs. result type.

\begin{tabular}{|c|c|c|c|c|}
\hline Metric & Condition & Mean & $t$ & $p$-Value \\
\hline \multirow{6}{*}{ FC (times) } & ASO ads & 17.68 & \multirow{2}{*}{-5.039} & \multirow{2}{*}{0.000} \\
\hline & ASO results & 34.36 & & \\
\hline & PRO ads & 20.48 & \multirow{2}{*}{-2.830} & \multirow{2}{*}{0.007} \\
\hline & PRO results & 29.55 & & \\
\hline & PRE ads & 20.67 & \multirow{2}{*}{-3.957} & \multirow{2}{*}{0.000} \\
\hline & PRE results & 34.26 & & \\
\hline \multirow{6}{*}{ FFD (in ms) } & ASO ads & 195.64 & \multirow{2}{*}{-3.199} & \multirow{2}{*}{0.003} \\
\hline & ASO results & 385.36 & & \\
\hline & PRO ads & 189.69 & \multirow{2}{*}{-1.300} & \multirow{2}{*}{0.201} \\
\hline & PRO results & 240.24 & & \\
\hline & PRE ads & 224.67 & \multirow{2}{*}{-1.871} & \multirow{2}{*}{0.068} \\
\hline & PRE results & 302.42 & & \\
\hline \multirow{6}{*}{ TFD (in ms) } & ASO ads & 5217.50 & \multirow{2}{*}{-5.603} & \multirow{2}{*}{0.000} \\
\hline & ASO results & $11,103.66$ & & \\
\hline & PRO ads & 6421.41 & \multirow{2}{*}{-2.639} & \multirow{2}{*}{0.012} \\
\hline & PRO results & 9636.89 & & \\
\hline & PRE ads & 6360.72 & \multirow{2}{*}{-3.577} & \multirow{2}{*}{0.001} \\
\hline & PRE results & $10,734.53$ & & \\
\hline \multirow{6}{*}{ TVD (in ms) } & ASO ads & 5625.23 & \multirow{2}{*}{-5.893} & \multirow{2}{*}{0.000} \\
\hline & ASO results & $12,348.95$ & & \\
\hline & PRO ads & 7024.70 & \multirow{2}{*}{-2.608} & \multirow{2}{*}{0.012} \\
\hline & PRO results & $10,484.02$ & & \\
\hline & PRE ads & 6862.40 & \multirow{2}{*}{-3.678} & \multirow{2}{*}{0.001} \\
\hline & PRE results & $11,771.84$ & & \\
\hline \multirow{6}{*}{ Clicks (times) } & ASO ads & 0.25 & \multirow{2}{*}{-4.168} & \multirow{2}{*}{0.000} \\
\hline & ASO results & 1.34 & & \\
\hline & PRO ads & 0.50 & -1936 & 0059 \\
\hline & PRO results & 0.98 & 1.000 & \\
\hline & PRE ads & 0.35 & -3085 & 0004 \\
\hline & PRE results & 1.07 & & \\
\hline
\end{tabular}

To check whether there were differences in the number of clicks on the ad sets and the organic results, another paired/dependent sample $t$-test for mean differences was performed. The results show general differences in the clicking behavior of the subjects on the ad sets and the organic result sets. The most significant difference is seen for the ASO condition $(t=-4.168 ; p=0.000)$, where a higher number of clicks were reached $($ mean $=1.34)$ for the organic results.

It can also be seen that the average number of clicks on the AOI for the conditions with regulatory framing were higher for the PRO (mean $=0.50)$ and PRE (mean $=0.35)$ ad 
sets with respect to the ASO (mean $=0.25$ ) ad set, and lower for the PRO (mean $=0.98$ ), and PRE (mean $=1.07$ ) organic result sets with respect to the ASO (mean =1.34) condition.

From the above, it can be expected that the organic results will be recalled more strongly than the ads. From a paired $t$-test, it was found that the organic results were mostly recalled with respect to the ads in the case of ASO orientation $(\mathrm{t}=4.583$; $\mathrm{df}=14$; $p=0.000)$ and PRE orientation $(\mathrm{t}=2.824 ; \mathrm{df}=14 ; p=0.014)$. The results were confirmed by conducting a non-parametric Friedman test, which also showed a $1 \%$ significant difference $(p=0.002)$. Although the subjects remembered the organic results to a greater extent, it should be noted that $66.7 \%$ of the participants remembered having seen the ads. A more detailed analysis based on the user orientation or fit is given below.

\subsection{Differences in Attention and Click Behaviour between Sets of Ads Based on Regulatory Fit}

The assumption of normality was checked by applying the Shapiro-Wilk test to the dependent variables (eye metrics). Based on the regulatory fit, an analysis of variance (ANOVA) was applied for each metric. To check the results, a non-parametric KruskalWallis test was carried out. The conditions in which eye metrics showed significant or quasi-significant mean differences are discussed below.

Greater visual attention, measured in terms of FC (see Figure 8), was directed towards the set of PRO ads by subjects with the prevention orientation than among the PRO-oriented ones $(\mathrm{F}=7.277 ; \mathrm{df1} ; \mathrm{df} 2=42 ; p=0.010)$, a result that was opposite to that expected. The Kruskal-Wallis test showed that the difference in mean according to the approach for the set of PRO ads had a 5\% significance level (Kruskal-Wallis' $\mathrm{H}=5.674 ; p=0.017$ ).

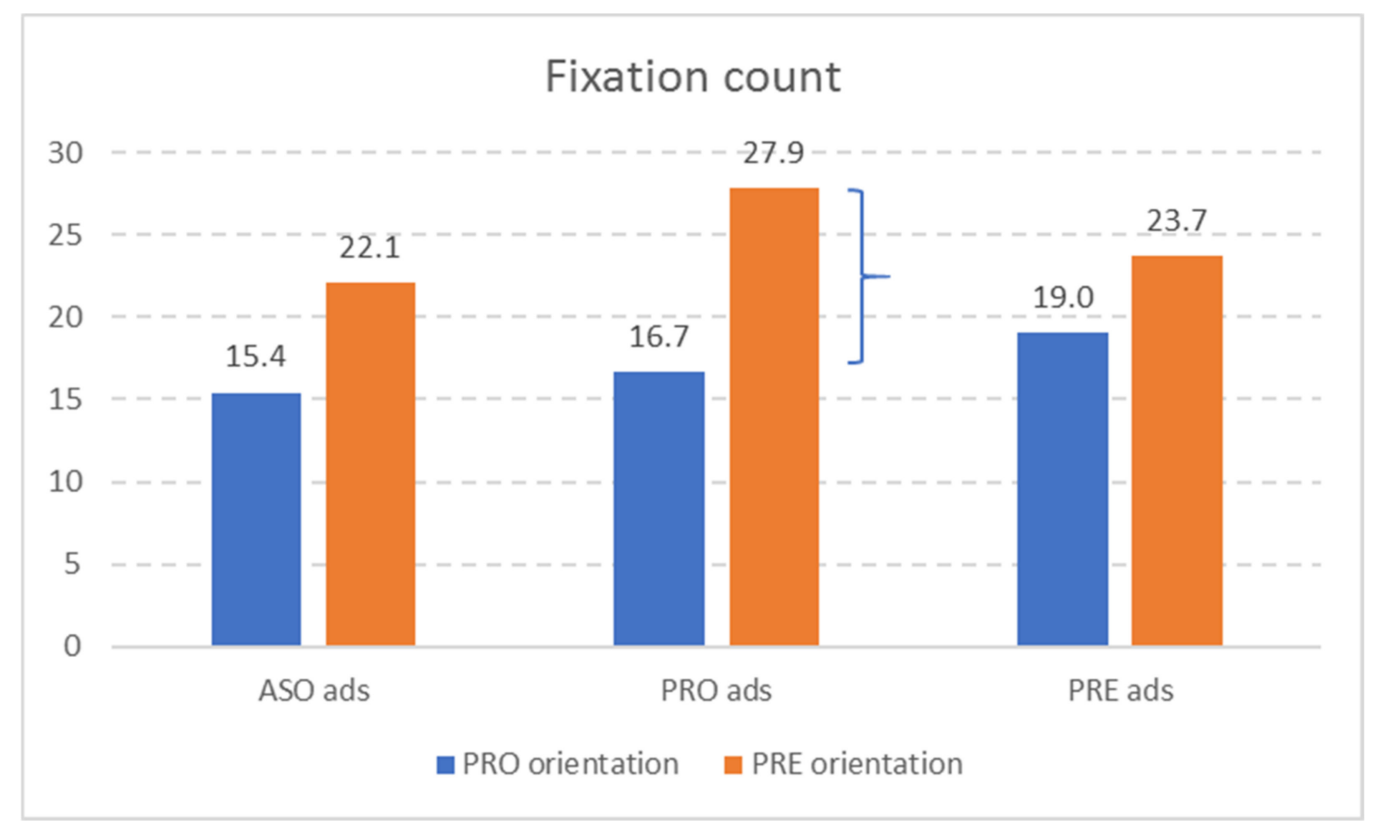

Figure 8. Mean graph for FC and ad type vs. regulatory orientation.

In contrast to the previous case, the set of PRE ads had a mean FFD that was significantly higher (see Figure 9 ) than the PRO-oriented ones ( $F=12.565$; df1; df2 = 41; $p=0.001)$. A Kruskal-Wallis test showed a difference in means with a $1 \%$ significance level (Kruskal-Wallis' $\mathrm{H}=13.448 ; p=0.000$ ). In addition, a significant difference was observed in the FFD for the ASO condition ( $\mathrm{F}=4.261$; df1; df2 = 38; $p=0.046)$, which was longer than for prevention-oriented individuals. However, this mean difference was not confirmed by a non-parametric test. 


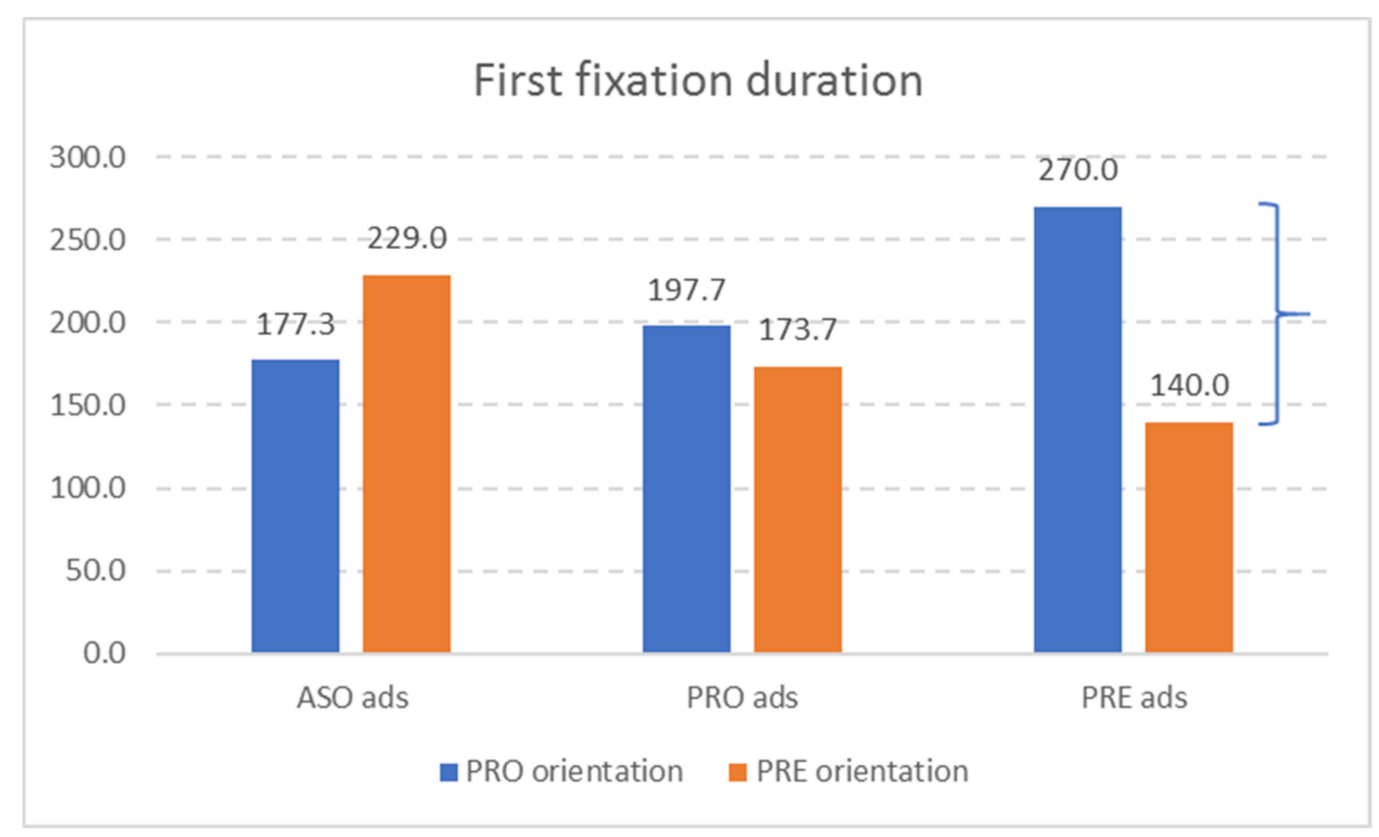

Figure 9. Mean graph for FFD and ad type vs. regulatory orientation (in ms).

It was, however, confirmed that the TFD for the PRO ads was greater for PRE-oriented subjects than those with a PRO orientation (see Figure 10), with significant differences $(\mathrm{F}=10.86 ; \mathrm{df1} ; \mathrm{df} 2=42 ; p=0.002)$. A check using a Kruskal-Wallis test showed that the difference in means according to the fit was confirmed in the set of PRO ads for a $5 \%$ significance level (Kruskal-Wallis' $\mathrm{H}=5.777 ; p=0.016$ ).

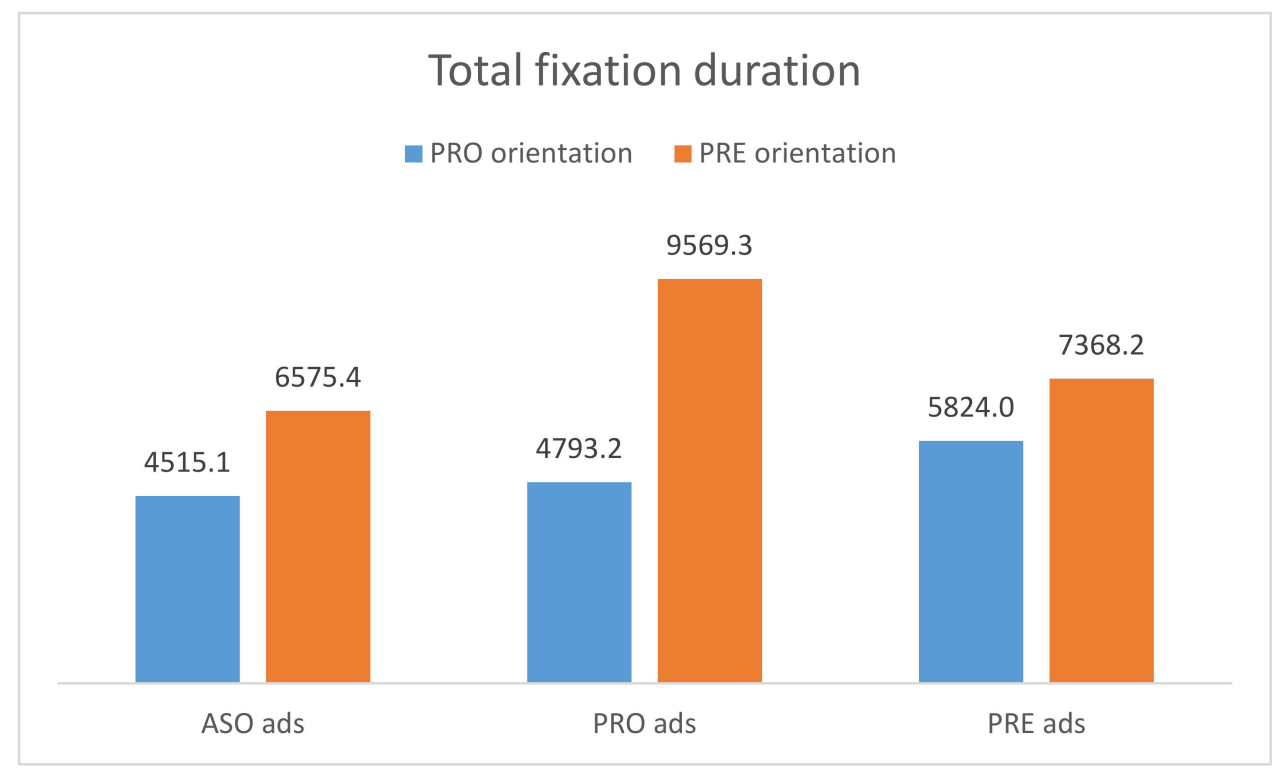

Figure 10. Mean graph for FFD and ad type vs. regulatory orientation (in ms).

It could also be observed (see Figure 11) that there were significant differences in the means of the TVD for the set of PRO ads according to the user type, where the mean was higher in the case of PRE-oriented subjects $(\mathrm{F}=11.857 ; \mathrm{df1}$; df $2=42 ; p=0.001)$. A Kruskal-Wallis test showed that the difference in means according to the approach for the set of PRO ads had a 5\% significance level (Kruskal-Wallis' $\mathrm{H}=6.018 ; p=0.014$ ). 


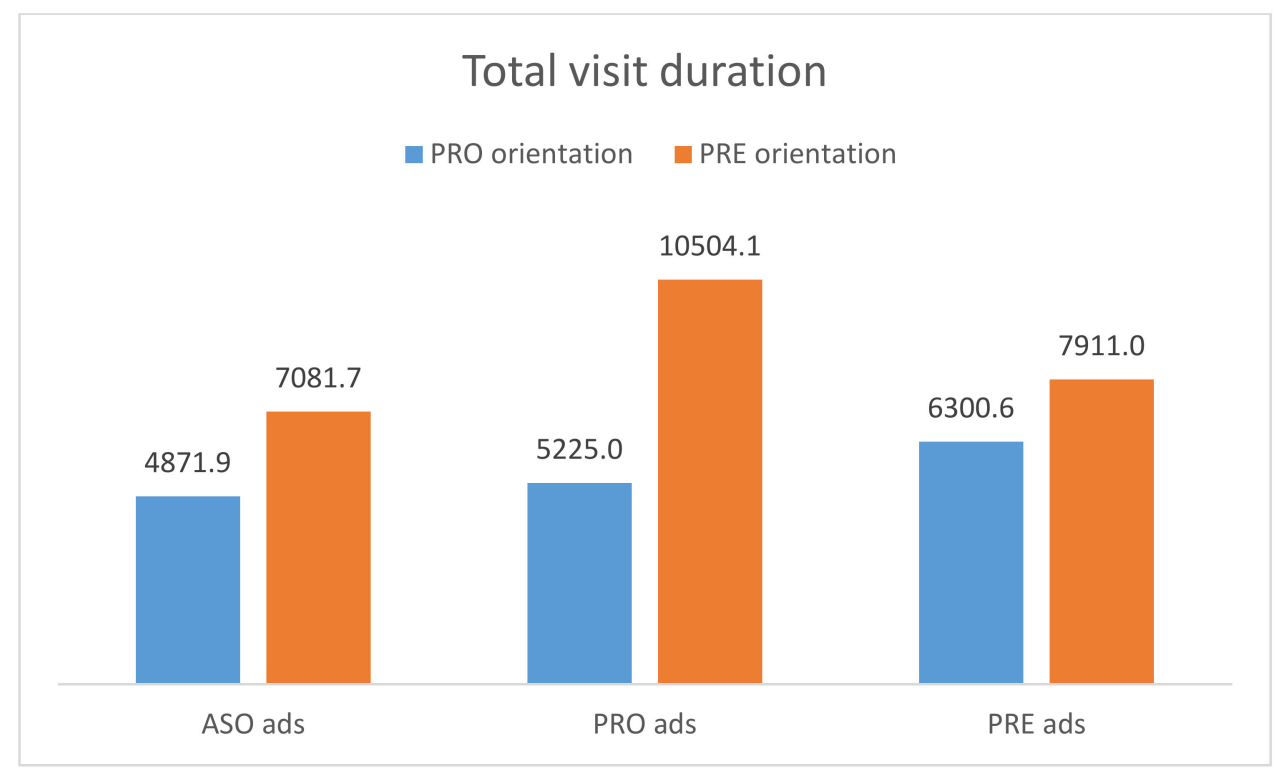

Figure 11. Mean graph for TVD and ad type vs. regulatory orientation (in ms).

An ANOVA was then carried out to check whether the regulatory fit was met for the clicking behavior. The regulatory fit factor was found to influence the number of clicks for the PRO ad set, with a $\%$ significance level ( $\mathrm{F}=12.385 ; \mathrm{df1} ; \mathrm{df} 2=42 ; p=0.001)$, and it can therefore be stated that there were differences in the click behavior of the subjects according to their orientation. A Kruskal-Wallis test confirmed the difference in means according to the fit for the PRO condition (Kruskal-Wallis' $\mathrm{H}=11.896 ; p=0.001$ ). In particular, the average number of clicks by the PRE-oriented subjects on the PRO ad set was higher than for the PRE-oriented subjects, as expected (see Figure 12).

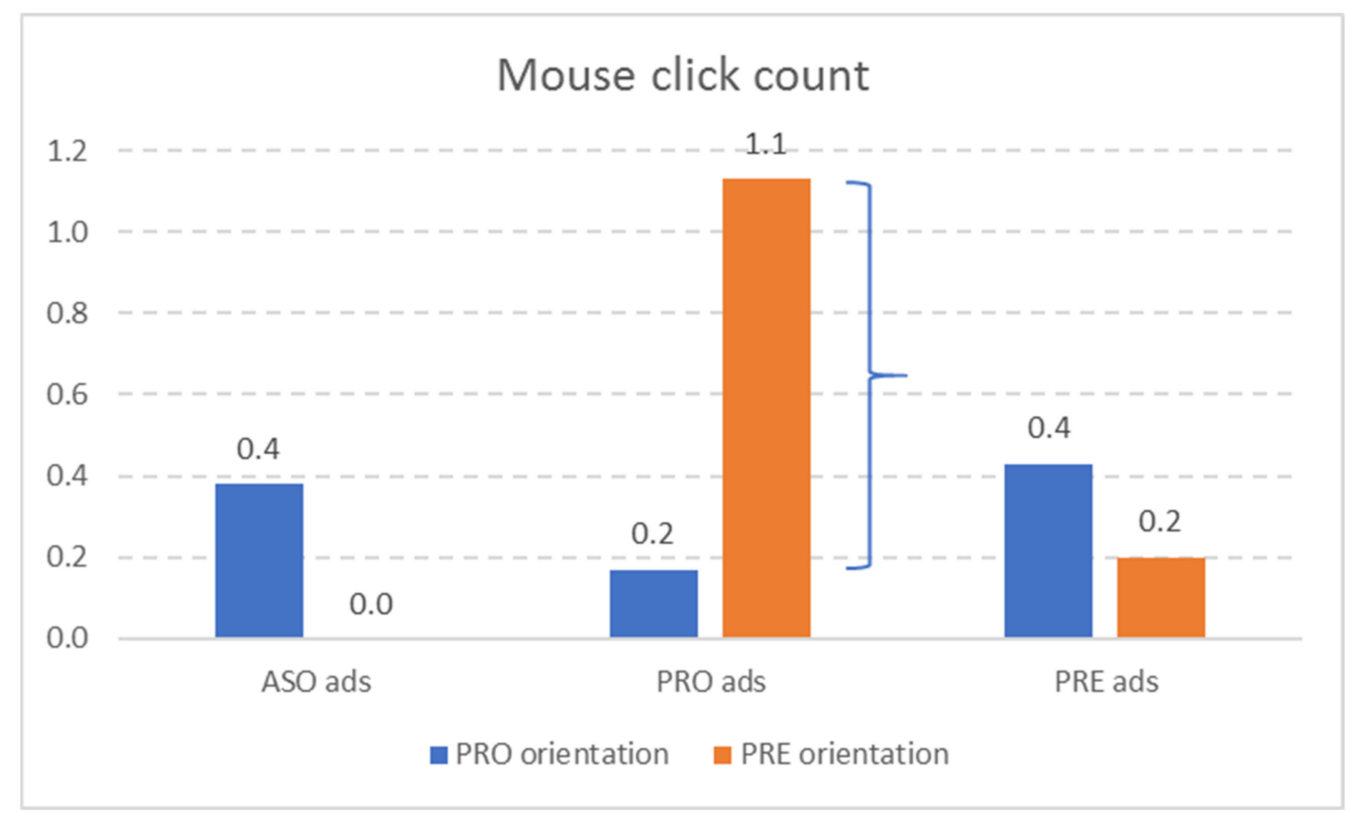

Figure 12. Mean graph for mcc and ad type vs. regulatory orientation.

From the above outcomes, we can conclude that there is no empirical evidence confirming Hypotheses $\mathrm{H} 1$ and $\mathrm{H} 2$, which postulate that more visual attention is paid to the ads and more clicking behavior is seen in individuals with regulatory fit (promotion or prevention) - that is, regulatory fit is not fulfilled for the case of eye-tracking metrics for Google searches. 


\subsection{Differences in Subjects' Attitudes towards Ads Based on Regulatory Fit}

For this analysis, a t-test for mean differences was performed, in which the average score for the classic attitude item (pleasant vs. unpleasant) for the PRO and PRE ad sets was used as the dependent variable and the regulatory fit (PRO and PRE orientation) as the independent variable. No significant differences were observed in the subjects' attitudes based on their regulatory fit in the case of the PRO ads $(t=0.356 ; \mathrm{df}=13 ; p=0.727)$, but the regulatory fit was met for the PRE ads with a $10 \%$ significance level $(t=-2.853$; $\mathrm{df}=13 ; p=0.014$ ). To support these results, a non-parametric Mann-Whitney's U test was carried out, which showed that there were no significant differences in the case of PRO ads $(\mathrm{Z}=-0.426 ; p=0.670)$, but there were significant differences for the PRE ads $(\mathrm{Z}=-2.252$; $p=0.024$, see Figure 13).

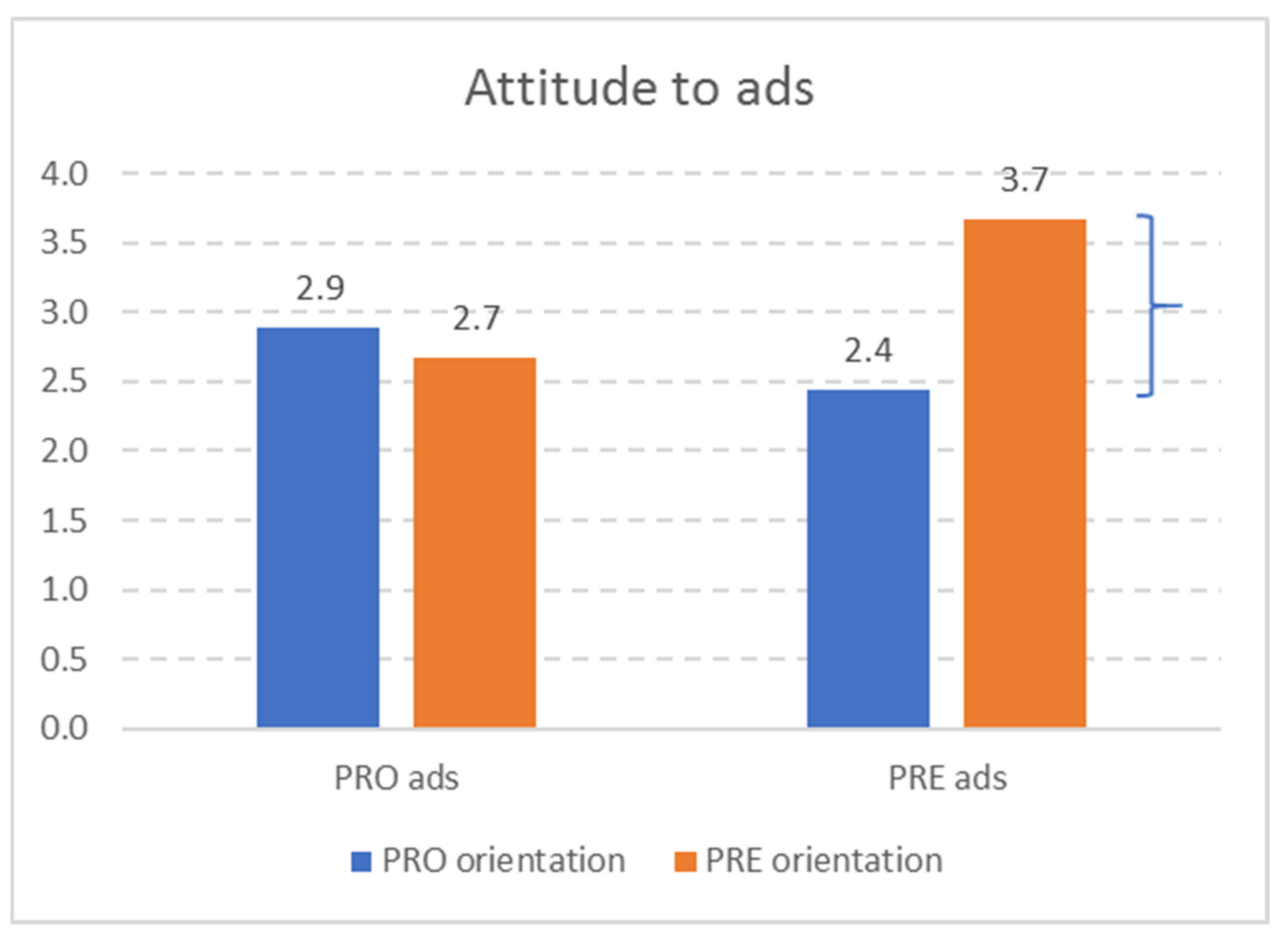

Figure 13. Graph of mean attitude to ads based on regulatory orientation.

We can therefore conclude that, in general, the regulatory fit is met, and that trends were identified as anticipated by the theory, but with very marked differences in the case of the PRE-framed ads.

\section{Conclusions}

First, and in line with prior results in the literature $[4,6,9,12,14,53-55]$ we found a tendency for users to prefer the organic results to the ads or not to avoid the results in front of the ads. It was also found that the subjects tended to remember the messages of the organic results to a greater extent, and this can be explained by the fact that they spent more time looking at them and clicked on them a higher number of times.

With respect to hypothesis $\mathrm{H} 1$, which postulated that subjects would pay greater attention to ads that matched their regulatory fit (promotion or prevention), it was not possible to verify whether the regulatory fit was met. A general comparison of the attention in the three conditions showed that visual attention was slightly increased in the PRO and PRE conditions compared to the ASO condition; this was mainly true for the PRO condition, and did not include the FFD metric. It can therefore be said that, despite the failure to comply with the fit, messages framed based on the regulatory fit did manage to attract slightly greater attention. 
More detailed conclusions derived from the fixation and visit metrics are described below. Regarding the number of fixations (FC), only the ads with promotional framing attracted a greater FC, but this was true only for the prevention-oriented subjects and not for the promotion-oriented ones. Thus, prevention-oriented subjects were targeted more often than promotion-oriented people, because the characteristics of their regulatory fit mean that they tend to be more hesitant in trying to find aspects that make them feel safe; to achieve this, they examined both types of ads in an exhaustive manner, especially the more promotional ones. In addition, they have less process for the elaboration of the information. Concerning the duration of the first fixation (FFD), the promotion-oriented subjects looked at the prevention ads for longer the first time they saw them, so the regulatory fit in this condition was not met. However, our analysis showed that although the promotion subjects did look at the promotion ads for longer the first time, the difference was not significant. This may be because 'promoter' subjects tend to be more enthusiastic about their actions and have a greater process for engaging with information on a day-to-day basis, including preventive ads. This finding may also be due to the process of message elaboration, as a higher level of understanding of the message may influence the time taken by the user to interpret it. These users make decisions more quickly, as they are more enthusiastic about making decisions and seek success and profit. In relation to the total length of fixation (TFD), prevention-oriented individuals looked at the ads for longer in general; this may be due to their tendency to look for safety, which may influence the time needed to feel confident in a decision. Because they have slower information processing, they may tend to take longer to decide. In the promotion condition, the regulatory fit was not met, as these users spent more time on ads that did not fit with their orientation (PRE). The results indicate that the framing of the message does help subjects to fixate for slightly longer on the ads. For the total length of visit (TVD), the results were very similar to those for TFD. These outcomes show that regulatory fit was not fulfilled from the point of view of visual attention, and hence hypothesis $\mathrm{H} 1$ does not hold.

For hypothesis H2, which stated that there would be differences in clicking behavior when the regulatory fit was met, we can conclude that this fit was not met as well. Prevention-focused subjects clicked more often on the set of promotion-oriented ads, and there were no significant differences in the number of clicks by promotion-focused subjects on the ads with their orientation. Although the research hypotheses could not be verified in this case, an interesting discussion of results was presented in response to the proposed objectives, and these were resolved in a favorable manner.

\section{Managerial Implications}

Despite recent research on the effectiveness of advertising on websites [40-42] and on search engines in general [4], business reality shows us that this issue is a fundamental question for companies because of the high amounts that are invested to appear in the top positions on search platforms (e.g., Google, Bing, Yandex, Yahoo! Search). Our findings have managerial implications for both the companies that operate the platforms and the marketers that use the platforms to advertise products.

On the one hand, platform companies will have to assume that users will be more interested in obtaining information through the content of commercial actions (SEO) rather than promotions (SEM). On the other hand, sellers, in light of a similar approach, should incentivize the purchase of their products through actions that reinforce the content instead of increasing investments in search engine advertising, because, as we have seen from the results of this research, users prefer organic results to advertisements.

Our study also contributes to the definition of new methodologies to analyze the effect of advertising on the consumer experience, as well as adding to the identification of new variables that will allow measuring the effectiveness of advertising messages versus organic results in terms of visual attention or click behavior - that is, the product of transactional searches-from the consumer's perspective. In other words, it is possible to include appropriate and innovative methodologies in the process of developing/designing SERP, such 
as eye-tracking technology. Considering the effect of regulatory fit on attracting attention, online marketing firms should focus on finding out more attractive places to enhance the attention (and recall) processing stage in SEO or SEM strategies; in particular, messages framed based on the regulatory fit did manage to attract slight greater attention. Search engines have information to classify individuals according to this variable (regulatory fit), which can be very interesting for advertising companies. The results of this study will also be useful for individuals with special limitations (such as accessibility problems), which can translate into a reduction in the time needed to find a product in a SERP.

\section{Limitations and Future Research}

Like any research, this study was subject to several limitations that should be considered when generalizing the results, while recognizing their exploratory nature.

One of the problems that arose was related to the within-subject design, because each person was shown three different conditions, which could have repercussions in terms of a habituation effect. To mitigate the possible effect of the presentation of the first stimuli on the rest of the experiment, the order of display of the screens was randomized (counterbalanced design).

Second, the convenience sampling method, which was used in part due to the COVID19 pandemic, forced us to recruit subjects for the experiment without a complete balance between the types of subject. Hence, there was an imbalance between the number of people with each regulatory focus, resulting in a larger sample of participants with a promotion focus $(9 ; 60 \%)$ compared to a prevention focus $(6 ; 40 \%)$. With regard to the experimental design, a $3 \times 2$ between-group design is recommended-that is, three conditions (ad types) for each of the two focuses-forming six experimental groups. To do this, a pre-test would need to be carried out prior to the experiment to determine the natural regulatory fit of each subject. Afterwards, the subjects would be divided based on the two approaches or groups, which in turn would be divided into three groups. In each group, each person would see only one condition (ASO or PRO or PRE); this would isolate and control the stimuli as far as possible, and hence allow us to explain the types of response to it much more effectively.

Third, this research has the limitation of a relatively small sample size (15 participants), which could affect the accuracy of the results. Eye-tracking studies generally use relatively few participants, much like psychophysics or physiology studies [56]. The literature review, by Scott et al. [57], of previous eye-tracking studies found that, in general, experimental designs have used between 12 and 63 participants; and our sample size is close to the minimum. Future work should increase the number of participants to implement experiments to analyze the moderating effect of regulatory fit.

Fourth, the results could vary if a different city or country had been chosen for the search term ("hotels in Madrid"), but we found that all participants had visited this city at least once in their lives and having the same reference element mitigated the possible effect or bias of this confounding variable. Future studies could leave the tourist destination to the free choice of the participant.

Fifth, the study was focused on Spain - that is, a specific country with certain peculiarities compared to others. For future lines of research, it would be interesting to analyze if cultural differences affect the results. Another possible variant that could undoubtedly bring a very interesting contribution is to compare a group of Westerners with participants from the Middle East. This would allow the verification of the conjectural Western bias for the right side of the webpages and the tendency to focus more on banners or secondary information on this side [58] because Middle Eastern participants are accustomed to reading from right to left and seeing banners on the opposite side of the web.

Sixth, additional classification variables, such as gender, age or generation, educational level, or level of experience could be considered for a more in-depth analysis of sociodemographic moderating effects. The level of engagement the user has with the 
product/website, as well as the user's reaction to it, should also be considered as potential mediating effects.

Finally, one of the aspects that made the experiment less natural was the fact that the subjects could not move from one search webpage to another when clicking on results that matched what they were looking for. Although this was explained to the participants and understood by them, it was a dissonant element for most of them. However, it is common in such investigations that the environment is not a natural one for the subject-for example, a search for a hotel with no real intention of booking a stay.

Author Contributions: Conceptualization, F.M.-L.; Methodology, Y.-I.G.-R., C.P.-d.-1.-C.-A., and F.M.-L.; Software, Y.-I.G.-R., C.P.-d.-1.-C.-A., and F.M.-L.; Validation, F.M.-L. and F.L.-C.; Formal analysis, Y.-I.G.-R. and C.P.-d.-1.-C.-A.; Investigation, E.H.-C. and F.M.-L.; Resources, F.M.-L. and F.L.-C.; Data curation, Y.-I.G.-R., C.P.-d.-1.-C.-A., and F.M.-L.; Writing-original draft preparation, Y.-I.G.-R. and C.P.-d.-1.-C.-A.; Writing-review and editing, E.H.-C. and F.ML.; Supervision, F.M.-L. and E.H.-C.; Project administration, F.M.-L. and F.L.-C.; Funding acquisition, F.M.-L. and F.L.-C. All authors have read and agreed to the published version of the manuscript.

Funding: This research was partly funded by national funding from the Spanish National R+D+I Research Program, through the NeuroTourism project (grant no. ECO2017-88458-R) and the Andalusian $\mathrm{R}+\mathrm{D}+\mathrm{I}$ Research Program, through the "Research in NeuroSOCOM" project (grant no. B-SEJ-209-UGR18).

Institutional Review Board Statement: Not applicable.

Informed Consent Statement: Informed consent was obtained from all subjects involved in the study.

Data Availability Statement: The data presented in this study are available on request from the corresponding author. The data are not publicly available due to privacy.

Conflicts of Interest: The authors declare no conflict of interest.

\section{Appendix A}

\section{Regulatory Orientation Scale. Source: Higgins et al. [29]}

1. Compared to most people, are you typically unable to get what you want out of life?

2. Growing up, would you ever "cross the line" by doing things that your parents would not tolerate?

3. How often have you accomplished things that got you "psyched" to work even harder?

4. Did you get on your parents' nerves often when you were growing up?

5. How often did you obey rules and regulations that were established by your parents?

6. Growing up, did you ever act in ways that your parents thought were objectionable?

7. Do you often do well at different things that you try?

8. Not being careful enough has gotten me into trouble at times.

9. When it comes to achieving things that are important to me, I find that I don't perform as well as I ideally would like to do.

10. I feel like I have made progress toward being successful in my life.

11. I have found very few hobbies or activities in my life that capture my interest or motivate me to put effort into them.

\section{References}

1. Nabout, N.A.; Lilienthal, M.; Skiera, B. Empirical Generalizations in Search Engine Advertising. J. Retail. 2014, 90, 206-216. [CrossRef]

2. Statista. Opinión de la Relevancia en Buscadores España. 2016. Available online: https:/ / es.statista.com/estadisticas/604057 /opinion-de-los-internautas-sobre-la-relevancia-de-resultados-online-en-espana/ (accessed on 14 March 2020).

3. Galán, J. Cuota de Mercado de Google en 2019. 2020. Available online: https:/ / www.josegalan.es/cuota-de-mercado-de-googleen-2019/ (accessed on 14 March 2020). 
4. Alanazi, A.O.; Sanderson, M.; Bao, Z.; Kim, J. The Impact of Ad Quality and Position on Mobile SERPs. In Proceedings of the 2020 Conference on Human Information Interaction and Retrieval, Vancouver, BC, Canada, 14-18 March 2020; pp. 318-322.

5. Fredlund, J.; Biedron, T. Is Trust in SEM an Intergenerational Trait? A Study of Sponsored Links and Generational Attitudes towards Them. Bachelor's Thesis, Halmstad University, Halmstad, Sweden, 2018.

6. Jansen, B.J.; Brown, A.; Resnick, M. Factors relating to the decision to click on a sponsored link. Decis. Support Syst. 2007, 44, 46-59. [CrossRef]

7. Koch, A.; Van Brakel, P.A. Paid search engine versus organic results: Young consumer preferences. In Proceedings of the 12th Annual Conference on World Wide Web App, Durban, South Africa, 21-23 September 2010; Available online: http: / / www.zaw3.co.za (accessed on 4 March 2021).

8. Li, Y.; Yuan, Z.; Liu, J. Effects of regulatory focus and user perception on search engine advertising avoidance. Soc. Behav. Pers. Int. J. 2017, 45, 999-1006. [CrossRef]

9. Murillo, E. Attitudes toward mobile search ads: A study among Mexican millennials. J. Res. Interact. Mark. 2017, 11, 91-108. [CrossRef]

10. Saura, J.; Reyes-Menendez, A.; Van Nostrand, C. Does SEO Matter for Startups? Identifying Insights from UGC Twitter Communities. Informatics 2020, 7, 47. [CrossRef]

11. Jansen, B.J.; Booth, D.L.; Spink, A. Determining the informational, navigational, and transactional intent of Web queries. Inf. Process. Manag. 2008, 44, 1251-1266. [CrossRef]

12. Marcos, M.; González-Caro, C. Comportamiento de los usuarios en la página de resultados de los buscadores. Un estudio basado en eye tracking. Prof. Inf. 2010, 19, 348-358. [CrossRef]

13. Mediative. The Evolution of Google Search Results Pages \& Their Effects on User Behaviour. Mediative. 2014. Available online: http:/ / pages.mediative.com/SERP-research (accessed on 4 March 2021).

14. Danescu-Niculescu-Mizil, C.; Broder, A.Z.; Gabrilovich, E.; Josifovski, V.; Pang, B. Competing for users' attention. In Proceedings of the 19th International Conference on Architectural Support for Programming Languages and Operating Systems, Raleigh, NC, USA, 26-30 April 2010; pp. 291-300.

15. Aktan, M.; Aydogan, S.; Aysuna, C. Web Advertising Value and Students' Attitude Towards Web Advertising. Eur. J. Bus. Manag. 2016, 8, 86-97.

16. Blake, T.; Nosko, C.; Tadelis, S. Consumer Heterogeneity and Paid Search Effectiveness: A Large-Scale Field Experiment. Econometrica 2015, 83, 155-174. [CrossRef]

17. Dai, D.; Luca, M. Effectiveness of Paid Search Advertising: Experimental Evidence. SSRN Electron. J. 2016, 17-25. [CrossRef]

18. Mowle, E.N.; Georgia, E.J.; Doss, B.D.; Updegraff, J.A. Application of regulatory focus theory to search advertising. J. Consum. Mark. 2014, 31, 494-502. [CrossRef]

19. Aaker, J.L.; Lee, A.Y. "I" Seek Pleasures and "We" Avoid Pains: The Role of Self-Regulatory Goals in Information Processing and Persuasion. J. Consum. Res. June 2001, 28, 33-49. [CrossRef]

20. Saura, J.R. Using Data Sciences in Digital Marketing: Framework, methods, and performance metrics. J. Innov. Knowl. 2021, 6, 92-102. [CrossRef]

21. Higgins, E.T. Beyond pleasure and pain. Am. Psychol. 1997, 52, 1280-1300. [CrossRef]

22. Gordeev, E.I. Generation of microseisms in the coastal area. Phys. Earth Planet. Inter. 1990, 63, 201-208. [CrossRef]

23. Crowe, E.; Higgins, E. Regulatory Focus and Strategic Inclinations: Promotion and Prevention in Decision-Making. Organ. Behav. Hum. Decis. Process. 1997, 69, 117-132. [CrossRef]

24. Idson, L.C.; Liberman, N.; Higgins, E.T. Imagining How You'd Feel: The Role of Motivational Experiences from Regulatory Fit. Pers. Soc. Psychol. Bull. 2004, 30, 926-937. [CrossRef]

25. Lee, A.Y.; Keller, P.A.; Sternthal, B. Value from Regulatory Construal Fit: The Persuasive Impact of Fit between Consumer Goals and Message Concreteness. J. Consum. Res. 2010, 36, 735-747. [CrossRef]

26. Avnet, T.; Higgins, E.T. How Regulatory Fit Affects Value in Consumer Choices and Opinions. J. Mark. Res. 2006, 43, 1-10. [CrossRef]

27. Cesario, J.; Grant, H.; Higgins, E.T. Regulatory Fit and Persuasion: Transfer From “Feeling Right". J. Pers. Soc. Psychol. 2004, 86, 388-404. [CrossRef] [PubMed]

28. Lee, A.Y.; Higgins, E.T. The persuasive power of regulatory fit. Soc. Psychol. Consum. Behav. 2009, 28, 319-333.

29. Higgins, E.T. Making a good decision: Value from fit. Am. Psychol. 2000, 55, 1217-1230. [CrossRef]

30. Xiong, J.; Jin, X.; Li, W. The Influence of Situational Regulation on the Information Processing of Promotional and Preventive Self-Regulatory Individuals: Evidence from Eye Movements. Front. Psychol. 2020, 11, 11. [CrossRef] [PubMed]

31. Fridman, I.; Ubel, P.A.; Higgins, E.T. Eye-tracking evidence shows that non-fit messaging impacts attention, attitudes and choice. PLoS ONE 2018, 13, e0205993. [CrossRef]

32. Kahneman, D.; Tversky, A. Prospect theory: An analysis of decision under risk. Econometrica 1979, 47, 263-292. [CrossRef]

33. Lee, A.Y.; Aaker, J.L. Bringing the Frame into Focus: The Influence of Regulatory Fit on Processing Fluency and Persuasion. J. Pers. Soc. Psychol. 2004, 86, 205-218. [CrossRef]

34. Petty, R.E.; Cacioppo, J.T. The Elaboration Likelihood Model of Persuasion. In Communication and Persuasion; Springer Science and Business Media LLC: Berlin/Heidelberg, Germany, 1986; pp. 1-24.

35. Moya, M. Persuasión y cambio de actitudes. Psicol. Soc. 1999, 11, 153-170. 
36. Blanco, C.F.; Sarasa, R.G.; Sanclemente, C.O. Effects of visual and textual information in online product presentations: Looking for the best combination in website design. Eur. J. Inf. Syst. 2010, 19, 668-686. [CrossRef]

37. Cabezudo, R.S.; Arranz, A.M.G.; Cillan, J.G. Designing Effective Websites: The Moderating Role of User Internet Experience. J. Internet Commer. 2008, 6, 35-60. [CrossRef]

38. Jones, L.W.; Sinclair, R.C.; Courneya, K.S. The Effects of Source Credibility and Message Framing on Exercise Intentions, Behaviors, and Attitudes: An Integration of the Elaboration Likelihood Model and Prospect Theory1. J. Appl. Soc. Psychol. 2003, 33, 179-196. [CrossRef]

39. Wedel, M.; Pieters, R. A Review of Eye-Tracking Research in Marketing. Rev. Mark. Res. 2017, 5, 123-147. [CrossRef]

40. Hernández-Méndez, J.; Muñoz-Leiva, F. What type of online advertising is most effective for eTourism 2.0? An eye tracking study based on the characteristics of tourists. Comput. Hum. Behav. 2015, 50, 618-625. [CrossRef]

41. Muñoz-Leiva, F.; Liébana-Cabanillas, F.; Hernández-Méndez, J. Etourism advertising effectiveness: Banner type and engagement as moderators. J. Serv. Mark. 2018, 32, 462-475. [CrossRef]

42. Muñoz-Leiva, F.; Hernández-Méndez, J.; Gómez-Carmona, D. Measuring advertising effectiveness in Travel 2.0 websites through eye-tracking technology. Physiol. Behav. 2019, 200, 83-95. [CrossRef]

43. Hervet, G.; Guérard, K.; Tremblay, S.; Chtourou, M.S. Is banner blindness genuine? Eye tracking internet text advertising. Appl. Cogn. Psychol. 2010, 25, 708-716. [CrossRef]

44. Schultheiß, S.; Lewandowski, D. How users' knowledge of advertisements influences their viewing and selection behavior in search engines. J. Assoc. Inf. Sci. Technol. 2021, 72, 285-301. [CrossRef]

45. Jouttijärvi, S. The Role of Creative Design in Capturing Consumer Attention with Effective Banner Advertising: An Eye Tracking Approach. Master's Thesis, LUT University, Lappeenranta, Finland, 2019.

46. Ewe, S.Y.; Lee, C.K.C.; Gul, F.A. Regulatory focus and investment advisers' recommending behavior. Int. J. Bank Mark. 2020, 39 , 107-126. [CrossRef]

47. Wibmer, A.; Wiedmann, F.; Seeber, I.; Maier, R. Adaptation of Visual Attention: Effects of Information Presentation in Idea Se-lection Processes. In Information Systems and Neuroscience; Springer: Berlin/Heidelberg, Germany, 2020; pp. 355-363.

48. National Statistics Institute INE. Population Census 2019. 2019. Available online: www.ine.es (accessed on 4 March 2021).

49. Statista. Distribución Porcentual de los Usuarios de Internet en España en 2019, por Edad. 2019. Available online: https: / / es.statista.com/estadisticas/812830/internautas-en-espana-por-edad/ (accessed on 26 February 2021).

50. Tang, L.R.; Jang, S.S.; Morrison, A. Dual-route communication of destination websites. Tour. Manag. 2012, 33, 38-49. [CrossRef]

51. Holmqvist, K.; Nyström, M.; Andersson, R.; Dewhurst, R.; Jarodzka, H.; van de Weijer, J. Eye Tracking: A Comprehensive Guide to Methods and Measures; Oxford University Press: Oxford, UK, 2011.

52. Jacob, R.J.; Karn, K.S. Eye Tracking in Human-Computer Interaction and Usability Research. In The Mind's Eye; Elsevier BV: Amsterdam, The Netherlands, 2003; pp. 573-605.

53. Buscher, G.; Dumais, S.T.; Cutrell, E. The good, the bad, and the random. In Proceedings of the 33rd International ACM SIGIR Conference on Research and Development in Information Retrieval-SIGIR'10, Geneva, Switzerland, 19-23 July 2010; pp. 42-49.

54. Gelfman, A. Methods of Web Traffic Acquisition Using; Tallinn University of Technology: Tallinn, Estonia, 2016.

55. Hotchkiss, G.; Alston, S.; Edwards, G. Eye Tracking Study; Enquiro: Boston, MA, USA; EyeTools: Springfield, MI, USA; Did-It: Melville, NY, USA, 2005.

56. Goldberg, J.; Wichansky, A. Eye tracking in usability evaluation: A practitioner's guide. In The Mind's Eye; North-Holland: California, CA, USA, 2003; pp. 493-516.

57. Scott, N.; Zhang, R.; Le, D.; Moyle, B. A review of eye-tracking research in tourism. Curr. Issues Tour. 2017, $22,1244-1261$. [CrossRef]

58. Simola, J.; Kuisma, J.; Öörni, A.; Uusitalo, L.; Hyönä, J. The impact of salient advertisements on reading and attention on web pages. J. Exp. Psychol. Appl. 2011, 17, 174-190. [CrossRef] 